\title{
Influence of the applied layer on the state of stress in a bimetallic perforated plate under two load variants
}

\author{
Mateusz Marcin Konieczny, Henryk Achtelik, Grzegorz Gasiak \\ Opole University of Technology, Poland \\ mateusmarcinkonieczny@wp.pl,kmpkm@po.edu.pl,g.gasiak@po.edu.pl
}

\begin{abstract}
The paper presents the results of the analysis of the influence of the applied plate layer on the state of stress in the bimetallic perforated plate. The finite element method ANSYS program was used for numerical calculations. The paper presents the results of stress tests for a single-layer clad plate made of S355J2 steel and a bimetallic perforated plate consisting of layers made of S355J2 steel and titanium. In addition, the study presents the results of the research on the influence of the method of loading, i.e. the concentrated force $P$ in the geometric center of the plate and the external pressure $q$ on the entire surface of the plate, and the method of support, i.e. free support and fixed, on the location of stress concentration zones in the bimetallic circular perforated plate. It has been shown that the presence of a perforated layer in the plate reduces the value of the equivalent von Mises stress by a minimum of approximately $30 \%$ in the base (steel) layer.
\end{abstract}

KEYwORDS. Applied layer; Base layer; Stress analysis; Numerical calculations; FEM.

\section{open 2 Access}

Citation: Konieczny, M. M., Achtelik, H., Gasiak G., Influence of the applied layer on the state of stress in a bimetallic perforated plate under two load variants, Frattura ed Integrità Strutturale, 56 (2021) 137-150.

Received: 25.01.2021

Accepted: 08.03 .2021 Published: 01.04.2021

Copyright: (C) 2021 This is an open access article under the terms of the CC-BY 4.0, which permits unrestricted use, distribution, and reproduction in any medium, provided the original author and source are credited.

\section{INTRODUCTION}

$\mathrm{I}$ $\mathrm{n}$ engineering structures, e.g. process equipment [1] or energy equipment [2], elements consisting of many layers and of many materials are used, i.e. bimetallic (plated) elements (Fig. 1) [3, 4], laminated elements [5] and composite elements [6]. Such structural elements may include layers made of structural steel, titanium alloys, brass, aluminum, nickel, but also of non-metallic materials such as polyethylene, glued wood, glass fibers and carbon fibers. These types of elements are most often used due to the improvement of corrosion resistance, appropriate frictional properties or special properties of thermal conductivity as well as the mechanical parameters of the structure in which such elements are present. The thickness of the applied layers, depending on the type of use of the plated sheet, may vary from $1.5-15 \%$ of the substrate thickness. Layering methods can be divided into two groups: cold plating, i.e. cold rolling, explosion [7, 8, 9] or hot plating, i.e. hot rolling, broaching, sintering. The use of elements consisting of many types of materials and multiple layers allows to obtain a material with specific properties that a single-layer material does not have. 


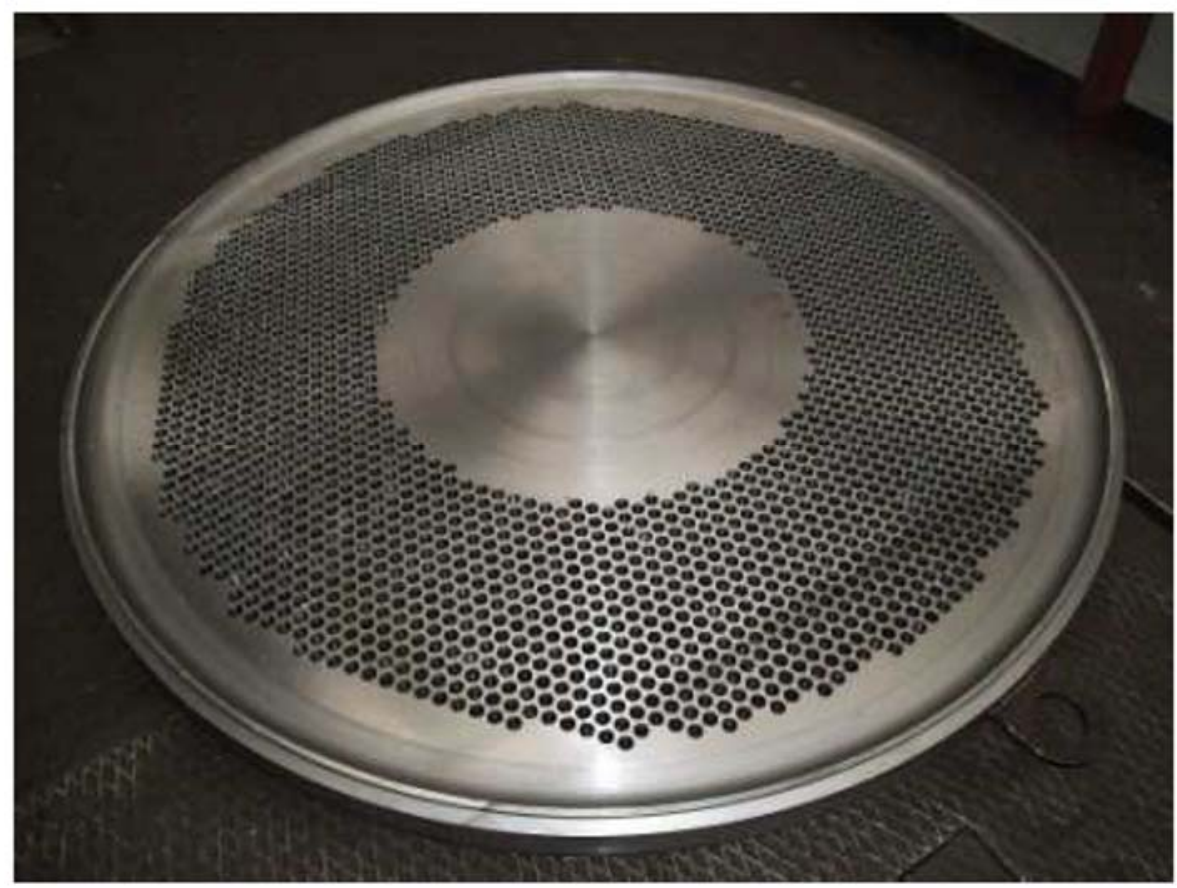

Figure 1: Model of bimetallic perforated plate [3].

In the works [10. 11], an analytical solution was presented using mathematical formulas enabling engineers to estimate the effort of the designed plated perforated plates subjected to various types of load. The results of these calculations were compared with the results obtained numerically using the finite element method and a good agreement was obtained. On the other hand, the work [12] presents the results of experimental research of the state of stress in a bimetallic perforated plate consisting of two layers, i.e. a steel and a titanium layer. It was found that the use of the ANSYS program enables the determination of the state of stress of the plated perforated plate at any point of the plate, i.e. on the bridge between the holes, around the holes, along the thickness of the titanium and steel layers. It also enables the determination of stress concentration zones, and thus the location of dangerous places in the designed plate. Experimental methods based on tensometry do not offer such possibilities.

In this work, among others, influence of the applied layer on the state of stress in a bimetallic circular perforated plate, freely supported at the edge and fixed at the edge, and loaded in the first case with a centrally concentrated force $P$ perpendicular to the plate surface and in the second case with external pressure $q$ over the entire surface of the plate. The research carried out at work was carried out on the basis of the application of the finite element method (FEM). The test results in the form of stress values presented in the paper can be used by engineers in the design of bimetallic perforated plates loaded perpendicular to their surface.

\section{MATERIAL AND GEOMETRY}

$\mathrm{F}$ or the calculations in the first case, a bimetallic perforated plate with dimensions: diameter $D=300 \mathrm{~mm}$ consisting of two layers, i.e. the base layer $\mathrm{B}$ in the form of structural steel with a thickness of $H=10 \mathrm{~mm}$ and the applied layer $A$ in the form of titanium with a thickness of $a=2.5 \mathrm{~mm}$ was adopted. (Fig. 2, 4b, 4d, 4f, 4h). However, in the second case, a perforated plate with the following dimensions was adopted: diameter $D=300 \mathrm{~mm}$ consisting of one layer, i.e. the base layer $B$ in the form of structural steel with a thickness of $H=10 \mathrm{~mm}$ (Fig. 2, 4a, 4c, 4e, 4g). 100 holes with different radii located on the plate. These holes were arranged in five circles with 20 holes in each circle. On the first outer circle, the plate had holes $d_{1}=20.5 \mathrm{~mm}$ in diameter and on the fifth, inner circle holes $d_{5}=9.5 \mathrm{~mm}$ in diameter (Fig. 2). Steel plate grade S355J2 was adopted as the base material, and titanium sheet was adapter as the applied material with the following mechanical and material parameters (Tab. 1) [13]. The materials used in the work, titanium and steel included in the bimetallic perforated plate, were modeled as elastic materials. 


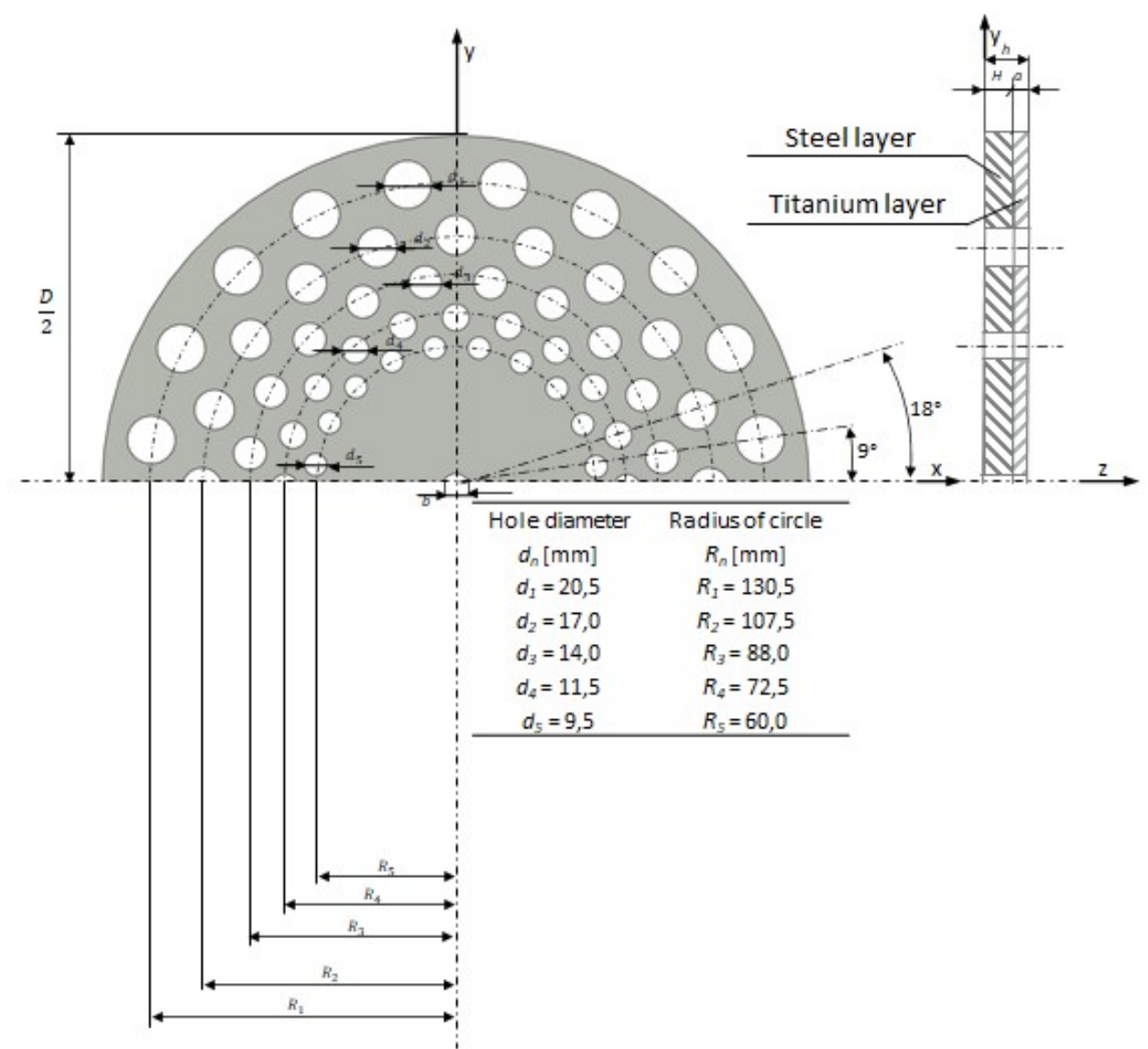

Figure 2: Model of bimetallic perforated plate consisting of steel thickness perforated plate $H$ and titanium perforated plate thickness $a$ containing holes with diameters $d_{1}, \ldots, d_{5}$.

\section{S355J2 steel and titanium}

Applied layer A - titanium

$\begin{array}{cccccc}\mathrm{R}_{e}[\mathrm{MPa}] & \mathrm{R}_{m}[\mathrm{MPa}] & E[\mathrm{GPa}] & v[-] & G[\mathrm{GPa}] & A 5[\%] \\ 189-215 & 308-324 & 100 & 0.37 & 36.5 & 43-56\end{array}$

$\begin{array}{lllll}\mathrm{C} & \mathrm{Fe} & \mathrm{N} & \mathrm{O} & \mathrm{Ti}\end{array}$

$\begin{array}{llllll}0.10 & 0.20 & 0.015 & 0.03 & 0.18 & \text { all }\end{array}$

Base layer B - S355J2 steel

$\begin{array}{ccccccc}\mathrm{R}_{e}[\mathrm{MPa}] & \mathrm{R}_{m}[\mathrm{MPa}] & E[\mathrm{GPa}] & v[-] & G[\mathrm{GPa}] & A 5[\%] \\ 382-395 & 598-605 & 220 & 0.30 & 84.6 & 24-34 \\ \mathrm{C} & \mathrm{Si} & \mathrm{Mn} & \mathrm{P} & \mathrm{S} & \mathrm{Cu} & \mathrm{Fe} \\ 0.22 & 0.55 & 1.60 & 0.025 & 0.025 & 0.45 & \text { all }\end{array}$

Table 1: Strength properties and chemical composition of S355J2 steel and titanium, where: $R_{e}-$ yield strength $[\mathrm{MPa}], \mathrm{R}_{m}-$ tensile strength $[\mathrm{MPa}], \mathrm{E}-$ Young's modulus [GPa], $v$ - Poisson's ratio [-], A5 - tensile elongation [\%]. 


\section{Calculation method}

$\mathrm{N}$ umerical calculations were carried out using the ANSYS finite element method software. It is a program for advanced numerical calculations using the finite element method (FEM). The three-dimensional 3D computational model of a circular plated perforated plate was created and discretized with the use of modeling and finite element mesh modeling in ANSYS [14]. Finite elements used for discretization were SOLID186 finite elements. Elements of the SOLID185 type are higher-order elements with a square shape function and well suited for modeling curved model boundaries without losing computational accuracy. Finite elements of this type are defined in the case of a tetrahedron-shaped element by 10 nodes with three degrees of freedom per node (UX, UY, UZ), i.e. translations in the nodes in the $\mathrm{x}, \mathrm{y}$, and $\mathrm{z}$ directions and in the case of a cube-shaped element by 20 nodes ( $\mathrm{I}, \mathrm{J}, \mathrm{K}, \mathrm{L}, \mathrm{M}, \mathrm{N}, \mathrm{O}, \mathrm{P}, \mathrm{Q}, \mathrm{R}, \mathrm{S}, \mathrm{T}$, $\mathrm{U}, \mathrm{V}, \mathrm{W}, \mathrm{X}, \mathrm{Y}, \mathrm{Z}, \mathrm{A}, \mathrm{B})$ with three degrees of freedom per node (UX, UY , UZ), i.e. translations in nodes in the $\mathrm{x}, \mathrm{y}$ and $\mathrm{z}$ directions. These elements can have any spatial orientation as well as take into account plasticity, creep, stress stiffness, large deflection and large strain. The calculation model for the clad perforated plate with the ring support had a total number of 3379707 finite elements, while the total number of nodes was 7027927. The entire plate had 25 finite element layers (twenty base plate layers and five layers of add-on plate) (Fig. 3). On the other hand, the calculation model in the case of a clad perforated plate without a support contained the total number of finite elements 2927283 , while the total number of nodes was 5029189. Tab. 2 shows the number of finite elements and nodes for each plate layer, i.e. for the steel plate layer and the titanium plate layer, and ring support (Fig. 3).

\begin{tabular}{cccc}
\hline & \multicolumn{2}{c}{ Number of finite elements and nodes } & \\
Sodes & 1998738 & Base layer B - steel & Applied layer A - titanium \\
Elements & 452424 & 3428852 & 1600337 \\
& & 2019704 & 907579 \\
\hline
\end{tabular}

Table 2: Number of finite elements and nodes in the analyzed plate.

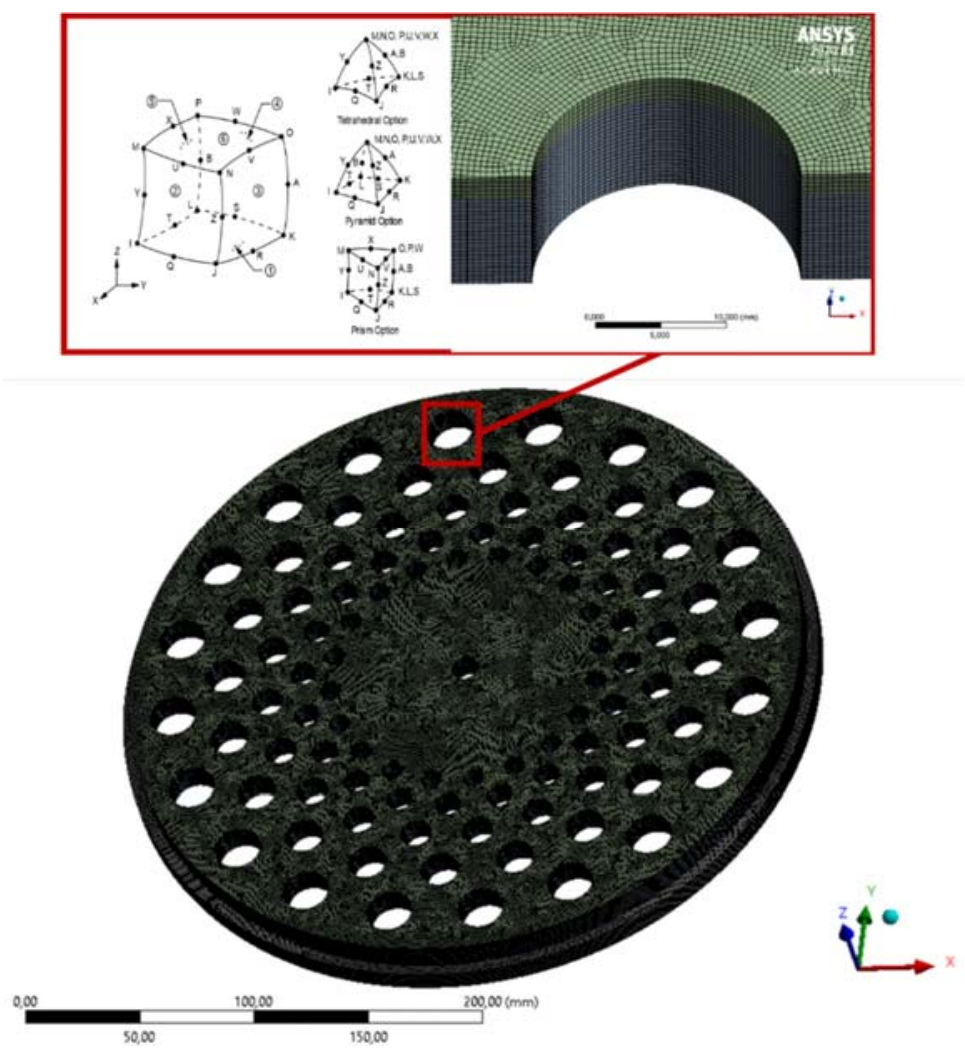

Figure 3: Finite elements of a bimetallic circular perforated plate in ANSYS program. 
The base layer of the B - steel plate is combined with the applied layer of the A - titanium plate by using the "connections" function, providing the option to bond two or more elements [14]. Details are presented in Appendix A. The calculations were made with an accuracy of $5 \%$.

\section{The Method of Supporting and Loading the Perforated Plate}

I $\mathrm{t}$ was assumed that the analyzed circular perforated plate is freely supported along its entire perimeter. The free support of the plate was achieved by designing a annular support on which a plated perforated plate was placed. Minimal friction contact is applied between the plate and the support. Then, in the first case, the analyzed plate was loaded centrally with the concentrated force $P$, normal to its surface. The load was applied around a hole with a diameter of $d=12$ $\mathrm{mm}$ located in the central part of the plate. The load was distributed over the diameter of $b_{1}=14 \mathrm{~mm}$ from the center of the plate with the use of a pressure stemp (Fig. $4 \mathrm{a}$ and $4 \mathrm{~b}$ ). In the second case, the analyzed plate was loaded with external pressure $q$ over the entire plate surface (Fig. $4 \mathrm{c}$ and $4 \mathrm{~d}$ ).

In the further part of the work, it was assumed that the analyzed circular plated perforated plate is fixed along its entire perimeter. The plate was fixed by limiting all degrees of freedom to the finite elements located on the outer contour of the perforated plate. Then, in the first case, the analyzed plate was loaded centrally with the concentrated force $P$, normal to its surface. The load was applied around a hole with a diameter of $d=12 \mathrm{~mm}$ located in the central part of the plate. The load was distributed over a diameter of $b_{1}=14 \mathrm{~mm}$ from the center of the plate with a pressure stamp (Fig. 4e and 4f). In the second case, the analyzed plate was loaded with the external pressure $q$ over the entire plate surface (Fig. $4 \mathrm{~g}$ and $4 \mathrm{~h}$ ).

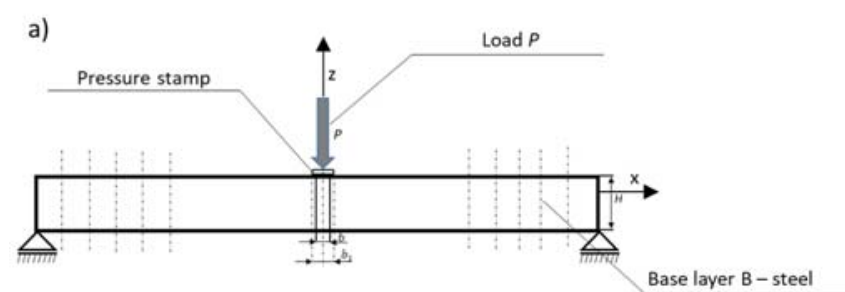

c)

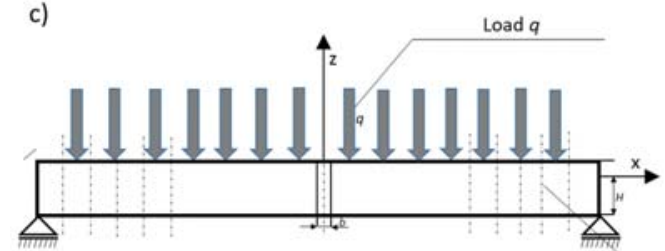

Base layer B-steel

e)

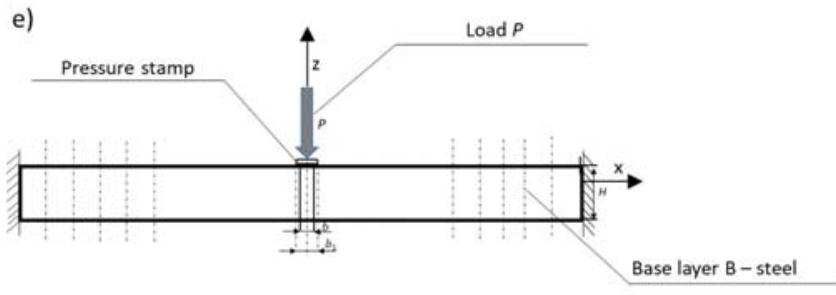

g)

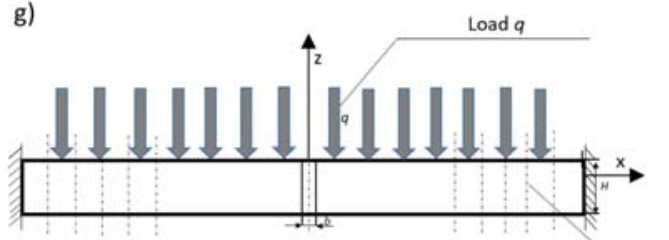

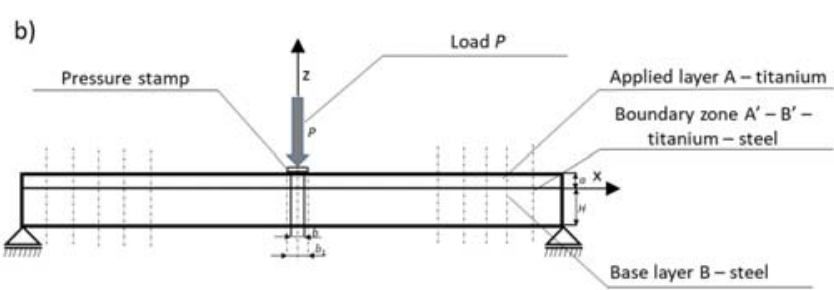

d)

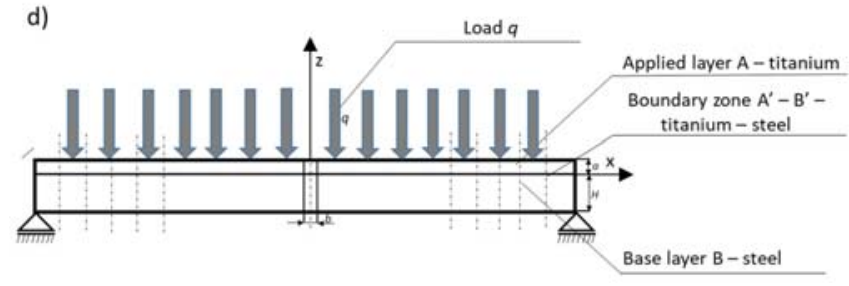

f)

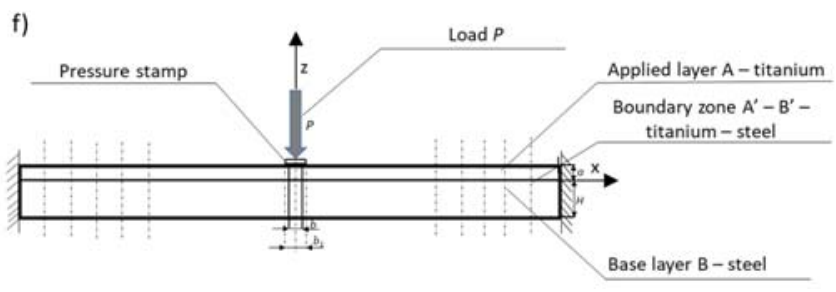

h)

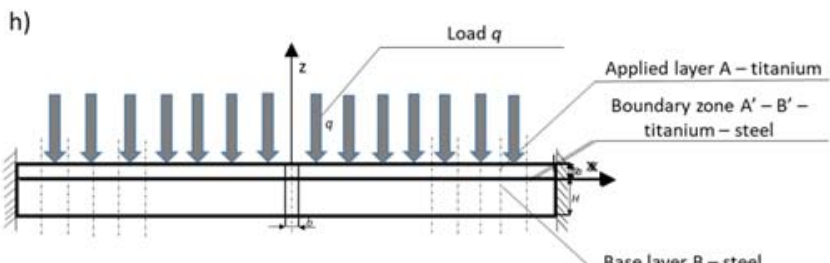

Base layer B-steel

Base layer B-steel

Figure 4: The method of supporting and loading the perforated plate. 


\section{STATE OF STRESS CALCULATION}

Bimetallic perforated plate (Fig. 4b-4h)

7 xamples of the equivalent von Mises stress distributions $\sigma_{\text {red }}^{n}$ given in $[\mathrm{MPa}]$ along the thickness of the bimetallic perforated plate are shown in Fig. 5. The figure shows the stress distribution in the perforated plate in the first case, simply supported on the annular support and loaded with a force $P=10 \mathrm{kN}$ (Fig. 5a), in the second case, simply supported on a annular support and loaded with external pressure $q=0.4 \mathrm{MPa}$ (Fig. $5 \mathrm{~b}$ ), in the third case fixed on the perimeter and loaded with a force $P=10 \mathrm{kN}$ (Fig. 5c), and in the fourth case fixed on the perimeter and loaded external pressure $q=0.4 \mathrm{MPa}$ (Fig. 5d) in the applied boundary zone A' - titanium, in the base boundary zone B' - steel and in the applied layer A and base layer B. The presented stress distribution was determined on the radius $r=R_{5}=60 \mathrm{~mm}$. The points AP and BP denote the maximum value of stress in the area of the hole in the layer of the applied plate A titanium and in the base layer of plate B - steel, respectively. On the other hand, the points AP' and BP' represent the maximum values of stress in the boundary zone of the plate, respectively in the boundary zone of the applied A' - titanium plate and in the boundary zone of the base B' - steel plate.
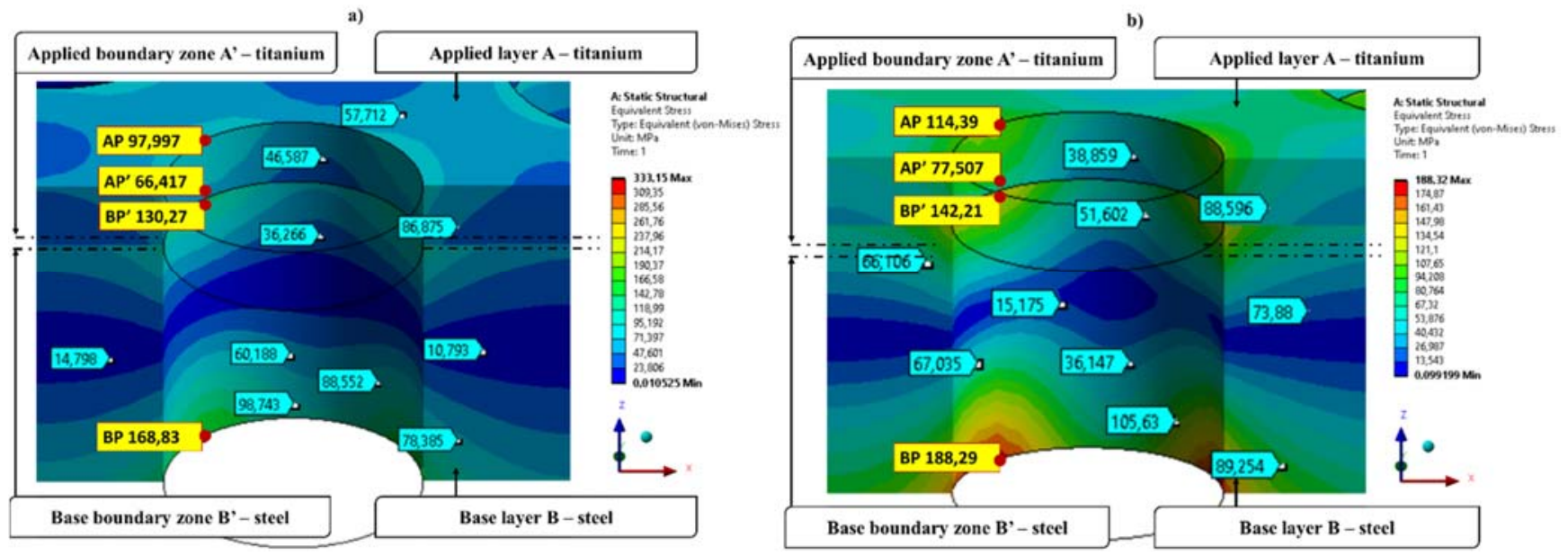

c)
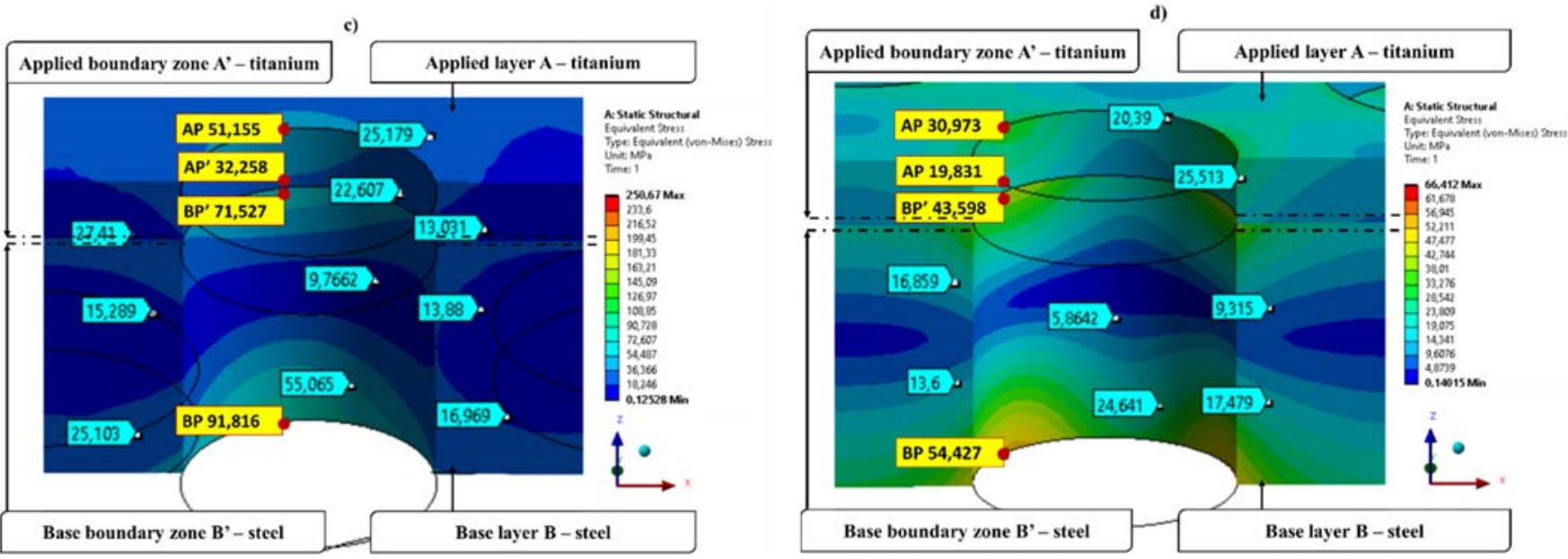

Figure 5. The distribution of the equivalent von Mises stresses $\sigma_{r e d}^{n}$ in a bimetallic perforated plate on the radius $r=R_{5}=60 \mathrm{~mm}$.

The most hazardous place in the considered circular bimetallic perforated plate with various methods of support and loading, where the highest stress concentration occurs, is at the hole radius $d_{5}=9.5 \mathrm{~mm}$ and the circle radius $r=R_{5}=60$ $\mathrm{mm}$. Tab. 3 summarizes the values and locations of stress concentration. 


\begin{tabular}{|c|c|c|c|c|}
\hline \multirow{3}{*}{ Points } & \multicolumn{4}{|c|}{ Values and locations of stress concentrations } \\
\hline & \multirow{2}{*}{$\begin{array}{l}\text { Equivalent von Mises stress } \\
\sigma_{\text {red } \max }[\mathrm{MPa}]\end{array}$} & \multicolumn{3}{|c|}{ Point with coordinates } \\
\hline & & $\mathrm{x}[\mathrm{mm}]$ & $\mathrm{y}[\mathrm{mm}]$ & $\mathrm{z}[\mathrm{mm}]$ \\
\hline \multicolumn{5}{|c|}{ Load $P=10 \mathrm{kN}-$ free supported } \\
\hline AP & 97.99 & 6.0 & 68.51 & 0.0 \\
\hline $\mathrm{BP}$ & 168.83 & 6.0 & 68.51 & 12.5 \\
\hline \multicolumn{5}{|c|}{ Load $q=0.4 \mathrm{MPa}-$ free supported } \\
\hline $\mathrm{AP}$ & 114.39 & -5.83 & 63.04 & 0.0 \\
\hline $\mathrm{BP}$ & 188.29 & -5.83 & 63.04 & 12.5 \\
\hline \multicolumn{5}{|c|}{ Load $q=0.4 \mathrm{MPa}-$ free supported } \\
\hline $\mathrm{AP}$ & 51.16 & 8.88 & $-54,91$ & 0.0 \\
\hline BP & 91.82 & 8.88 & -54.91 & 12.5 \\
\hline \multicolumn{5}{|c|}{ Load $P=10 \mathrm{kN}$ - fixed supported } \\
\hline AP & 30.98 & 5.32 & 62.50 & 0.0 \\
\hline $\mathrm{BP}$ & 54.43 & 5.32 & 62.50 & 12.5 \\
\hline
\end{tabular}

Table 3: Values and locations of stress concentrations in bimetallic perforated plate.

Single-layer perforated plate (Fig. $4 a-4 g$ )

Examples of the equivalent von Mises stress distributions $\sigma_{\text {red }}^{n}$ given in [MPa] along the thickness of a single-layer perforated plate are shown in Fig. 6. The figure shows the stress distribution in the first case, simply supported on a annular support and loaded with a force $P=10 \mathrm{kN}$ (Fig. 6a), in the second case, simply supported on a annular support and loaded with external pressure $q=0.4 \mathrm{MPa}$ (Fig. 6b), in the third case fixed on the perimeter and loaded with a force $P=10 \mathrm{kN}$ (Fig. $6 \mathrm{c}$ ), and in the fourth case fixed on the perimeter and loaded external pressure $\mathrm{q}=0.4 \mathrm{MPa}$ (Fig. 6d) in the base layer B. The presented stress distribution was determined on the radius $r=R_{5}=60 \mathrm{~mm}$. The BP point is the maximum value of stress in the hole zone in the base layer of the steel plate B.
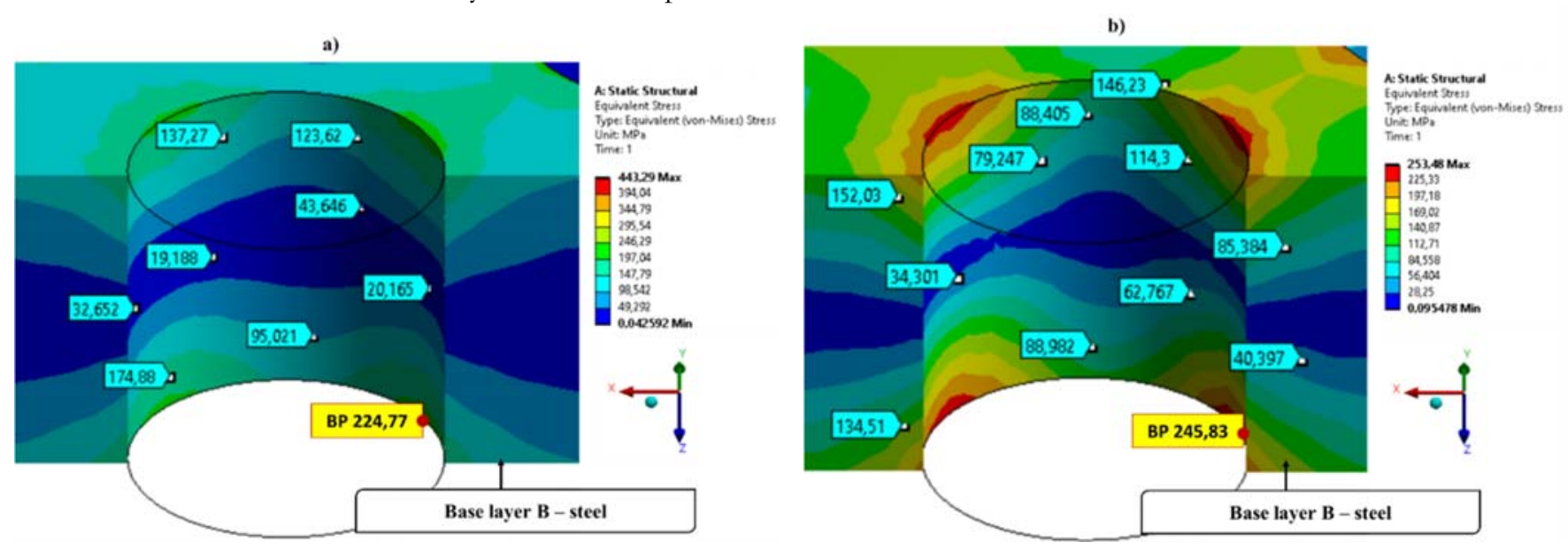
c)

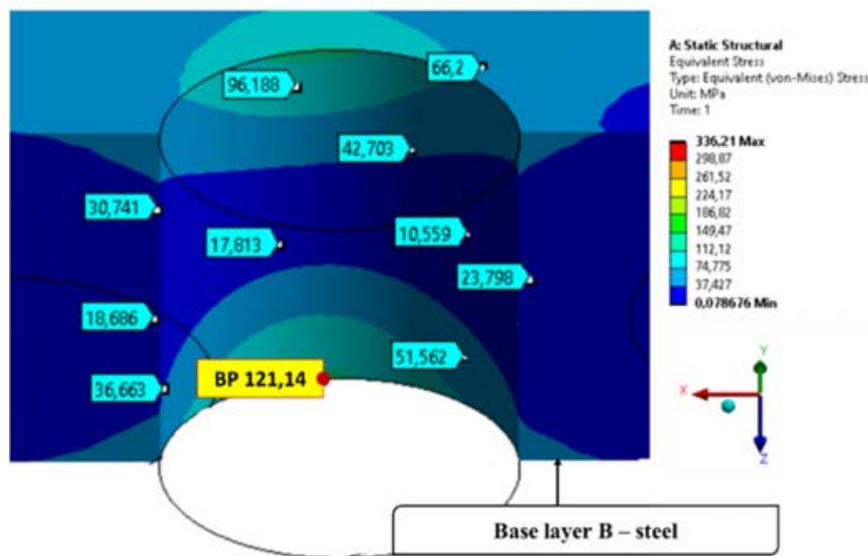

d)

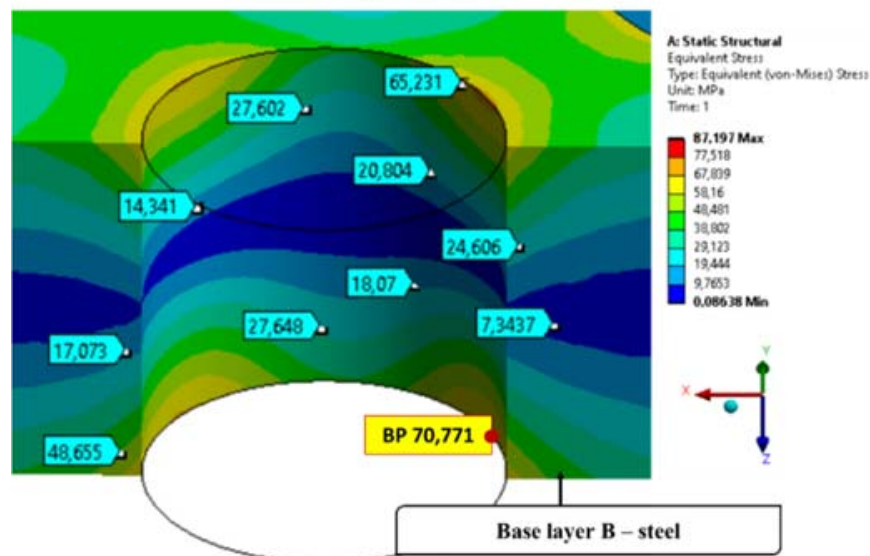

Figure 6. The distribution of the equivalent von Mises stresses $\sigma_{r e d}^{n}$ in a single-layer perforated plate on the radius $r=R_{5}=60 \mathrm{~mm}$.

The most hazardous place in the considered circular single-layer perforated plate with different methods of support and load, where the highest stress concentration occurs, is at the hole radius $d_{5}=9.5 \mathrm{~mm}$ and the circle radius $r=R_{5}=60 \mathrm{~mm}$. Tab. 4 summarizes the values and locations of stress concentration.

Values and locations of stress concentrations

\begin{tabular}{|c|c|c|c|c|}
\hline \multirow{2}{*}{ Points } & \multirow{2}{*}{$\begin{array}{l}\text { Equivalent von Mises stress } \\
\sigma_{\text {red } \max }[\mathrm{MPa}]\end{array}$} & \multicolumn{3}{|c|}{ Point with coordinates } \\
\hline & & $\mathrm{x}[\mathrm{mm}]$ & $\mathrm{y}[\mathrm{mm}]$ & $\mathrm{z}[\mathrm{mm}]$ \\
\hline \multicolumn{5}{|c|}{ Load $P=10 \mathrm{kN}-$ free supported } \\
\hline $\mathrm{BP}$ & 224.77 & 13.84 & 61.70 & 10.0 \\
\hline \multicolumn{5}{|c|}{ Load $q=0.4 \mathrm{MPa}-$ free supported } \\
\hline $\mathrm{BP}$ & 245.83 & 14.24 & 60.78 & 10.0 \\
\hline \multicolumn{5}{|c|}{ Load $q=0.4 \mathrm{MPa}-$ free supported } \\
\hline $\mathrm{BP}$ & 121.14 & -8.51 & -54.85 & 10.0 \\
\hline \multicolumn{5}{|c|}{ Load $P=10 \mathrm{kN}$ - fixed supported } \\
\hline $\mathrm{BP}$ & 70.77 & -14.20 & 61.37 & 10.0 \\
\hline
\end{tabular}

Table 4: Values and locations of stress concentrations in single-layer perforated plate.

\section{RESULTS OF THE RESEARCH}

$\mathrm{F}$ igs. 7-10 show the equivalent von Mises stresses $\sigma_{r d}^{n}$ along the radius $r$ given in [MPa], determined by the finite element method, both in the bimetallic and single-layer perforated plate. In the first case, simply supported on a annular support and loaded with a force $P=10 \mathrm{kN}$ (Fig. 7), in the second case simply supported on a annular support and loaded with external pressure $q=0.4 \mathrm{MPa}$ (Fig. 8), in the third case restrained on perimeter and loaded with a force $P=10 \mathrm{kN}$ (Fig. 9) and in the fourth case, fixed on the perimeter and loaded with an external pressure $q=0.4 \mathrm{MPa}$ (Fig. 10). 


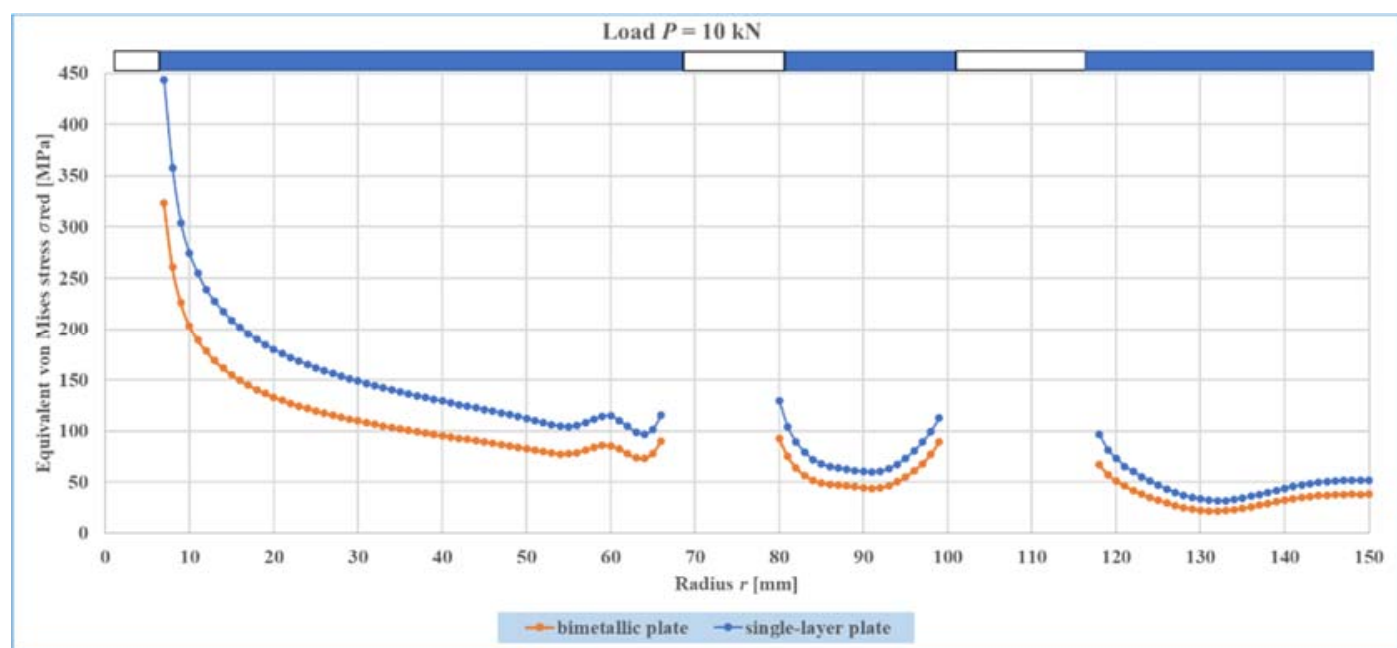

Figure 7: Courses of equivalent von Mises stress $\sigma_{\text {red }}^{n}$ in: a) a bimetallic perforated plate; b) a single-layer perforated plate, simply supported on a annular support and subjected to a load of $P=10 \mathrm{kN}$.

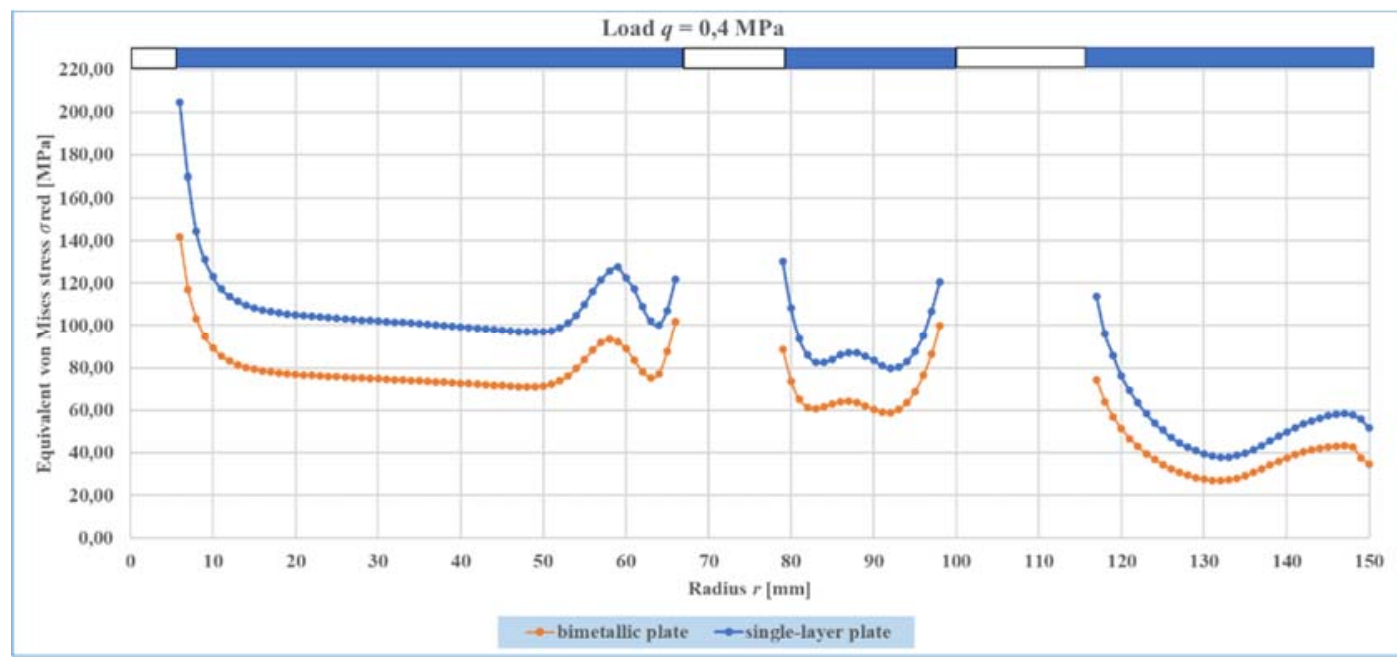

Figure 8: Courses of equivalent von Mises stress $\sigma_{\text {red }}^{n}$ in: a) a bimetallic perforated plate; b) a single-layer perforated plate, simply supported on a annular support and subjected to a load of $q=0.4 \mathrm{MPa}$.

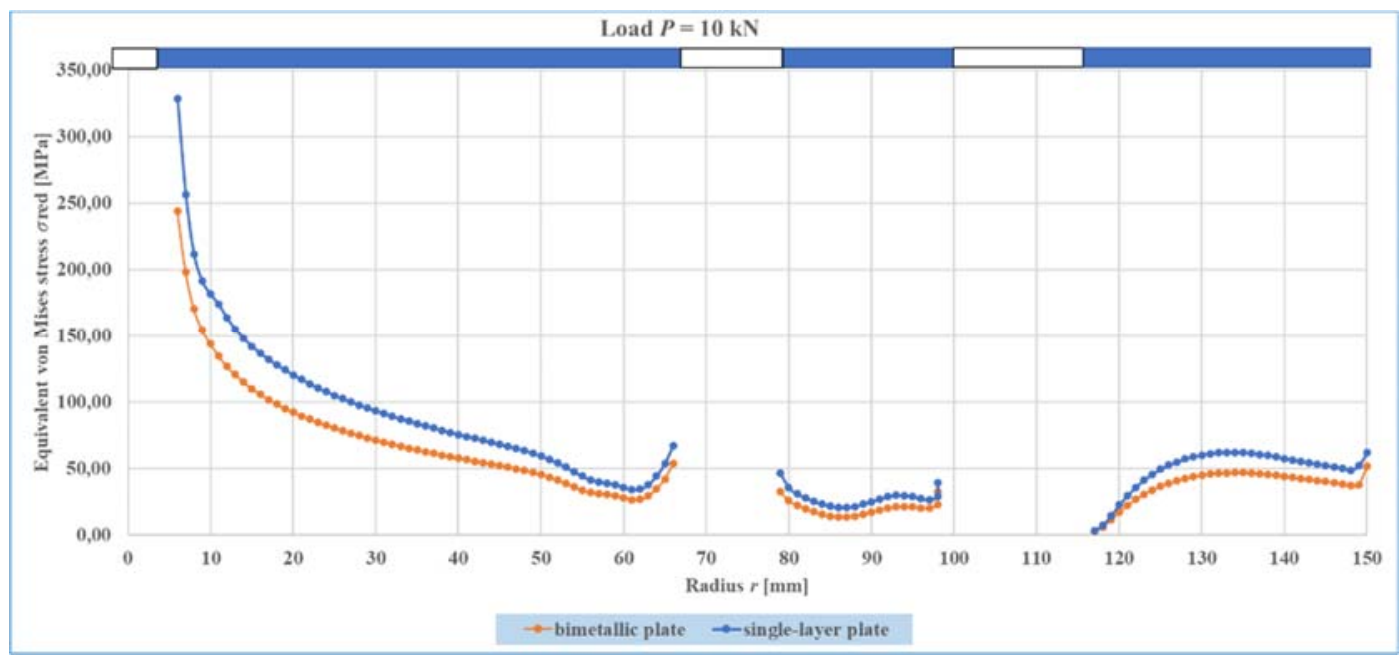

Figure 9: Courses of equivalent von Mises stress $\sigma_{\text {red }}^{n}$ in: a) a bimetallic perforated plate; b) a single-layer perforated plate, fixed on the perimeter and subjected to a load of $P=10 \mathrm{kN}$. 


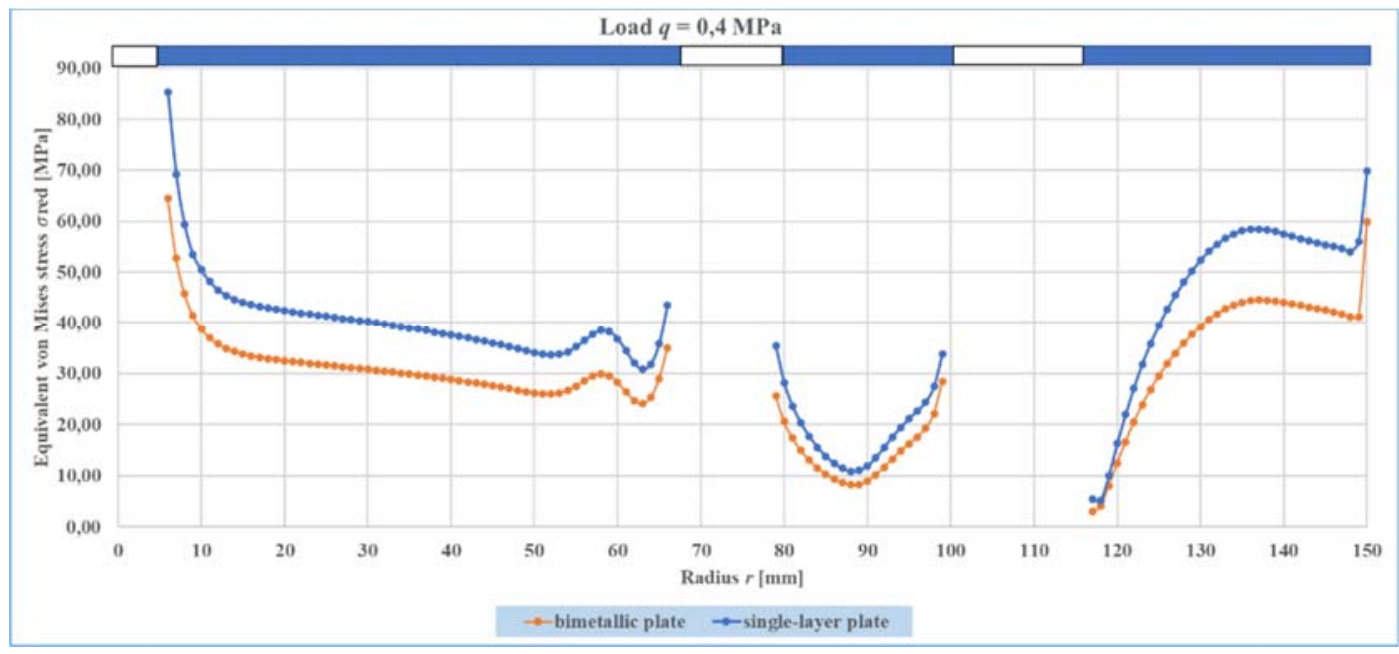

Figure 10: Courses of equivalent von Mises stress $\sigma_{\text {red }}^{n}$ in: a) a bimetallic perforated plate; b) a single-layer perforated plate, fixed on the perimeter and subjected to a load of $q=0.4 \mathrm{MPa}$.

Whereas, Figs. 11 - 14 show the percentage difference of changes in equivalent von Mises stresses $\delta \sigma_{\text {red }}^{n}$ determined along the radius $r$ given in [MPa], both in the bimetallic and single-layer perforated plate. In the first case, it is simply supported on a annular support and loaded with a force $P=10 \mathrm{kN}$ (Fig. 11), in the second case simply supported on a annular support and loaded with external pressure $q=0.4 \mathrm{MPa}$ (Fig. 12), in the third case it is fixed on perimeter and loaded with a force $P$ $=10 \mathrm{kN}$ (Fig. 13) and in the fourth case, fixed along the perimeter and loaded with an external pressure $q=0.4 \mathrm{MPa}$ (Fig. 14).

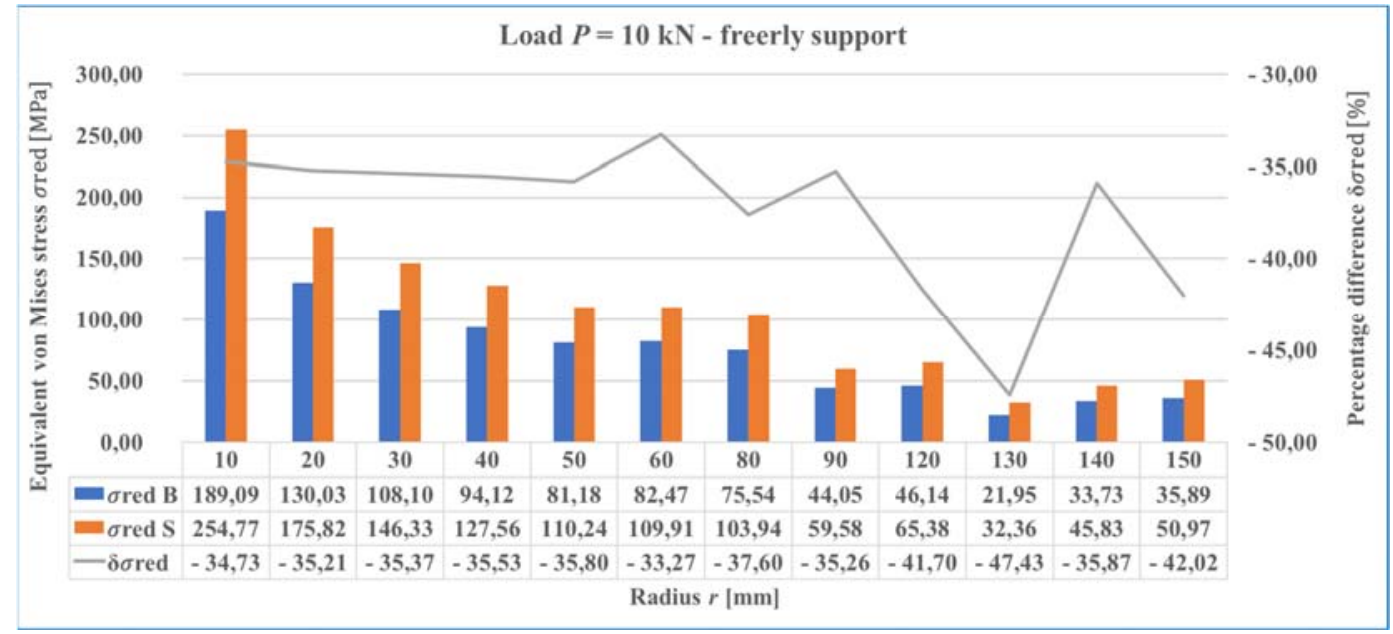

Figure 11: Percentage difference of changes in equivalent von Mises stresses $\delta \sigma_{\text {red }}^{n}$ determined in the bimetallic plate $\sigma_{\text {red }}^{n}$ and in the single-layer plate $\sigma_{\text {reds }}^{n}$, simply supported on the annular support and with a load of $P=10 \mathrm{kN}$.

The analysis of the courses of equivalent von Mises stress in the perforated plates presented in Figs. 7-10 shows that in all cases of loading and edge support, the equivalent von Mises stress $\sigma_{r d_{B}}^{n}$ is lower in the base layer of the bimetallic steel plate compared to the equivalent von Mises stress $\sigma_{r e d_{s}}^{n}$ in the same layer of a single-layer steel plate. The presence of a perforated titanium layer in the plate significantly increases the load-bearing capacity of the plate. Moreover, Figs. 11-14 show the courses of the percentage difference in the changes of the equivalent von Mises stresses $\delta \sigma_{r e d}^{n}$ determined in the 
bimetallic plate $\sigma_{r^{\prime} d_{B}}^{n}$ and the single-layer plate $\sigma_{r d_{s}}^{n}$ along its radius $r$ the percentage difference in equivalent von Mises stress for bimetallic and single-layer plates was determined from the relationship:

$$
\delta \sigma_{r e d}^{n}=\frac{\sigma_{r e d_{B}}^{n}-\sigma_{r e d_{S}}^{n}}{\sigma_{r e d_{B}}^{n}} * 100 \%
$$

where:

$\sigma_{\text {red }_{B}}^{n}$ - value of equivalent von Mises stress in the base layer B - steel bimetallic perforated plate;

$\sigma_{r e d_{s}}^{n}$ - the value of the equivalent von Mises stress in a single-layer perforated plate with a thickness equal to the base layer B - bimetallic steel plate.

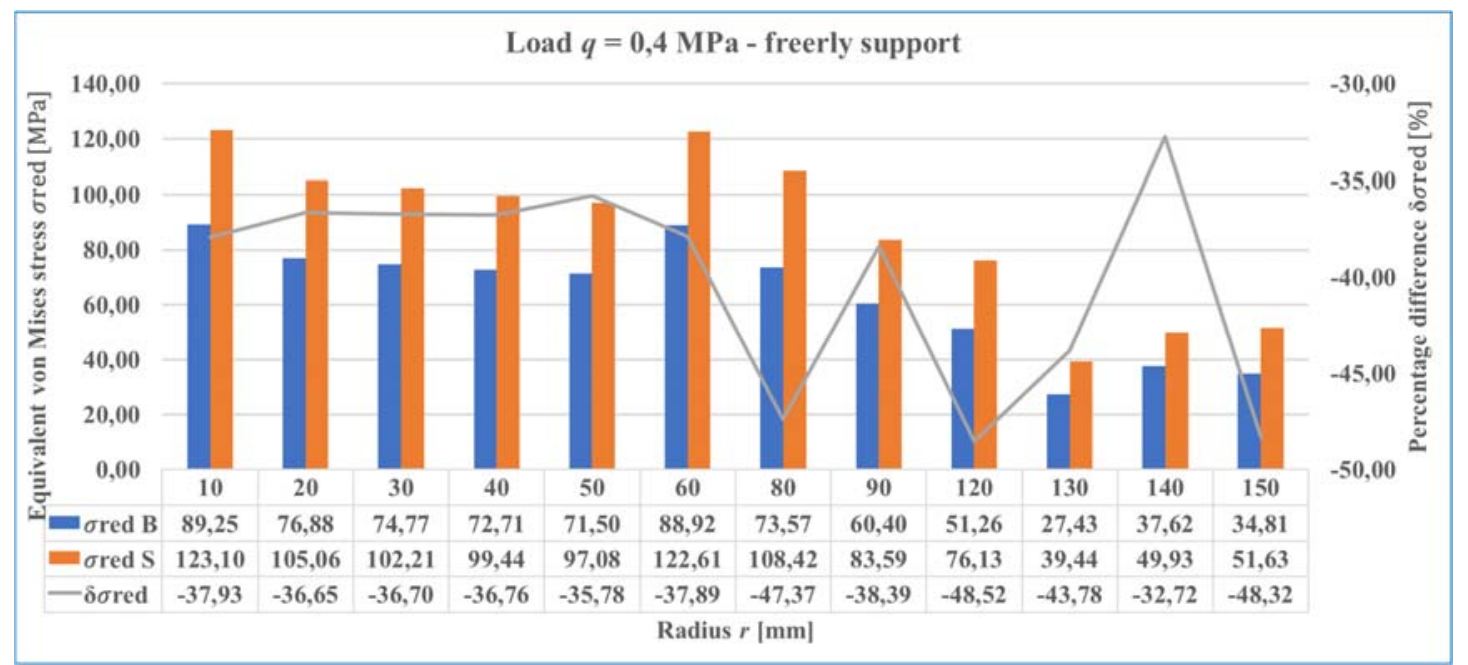

Figure 12: Percentage difference of changes in equivalent von Mises stresses $\delta \sigma_{\text {red }}^{n}$ determined in the bimetallic plate $\sigma_{\text {red }_{B}}^{n}$ and in the single-layer plate $\sigma_{\text {reds }}^{n}$, simply supported on the annular support and with a load of $q=0.4 \mathrm{MPa}$.

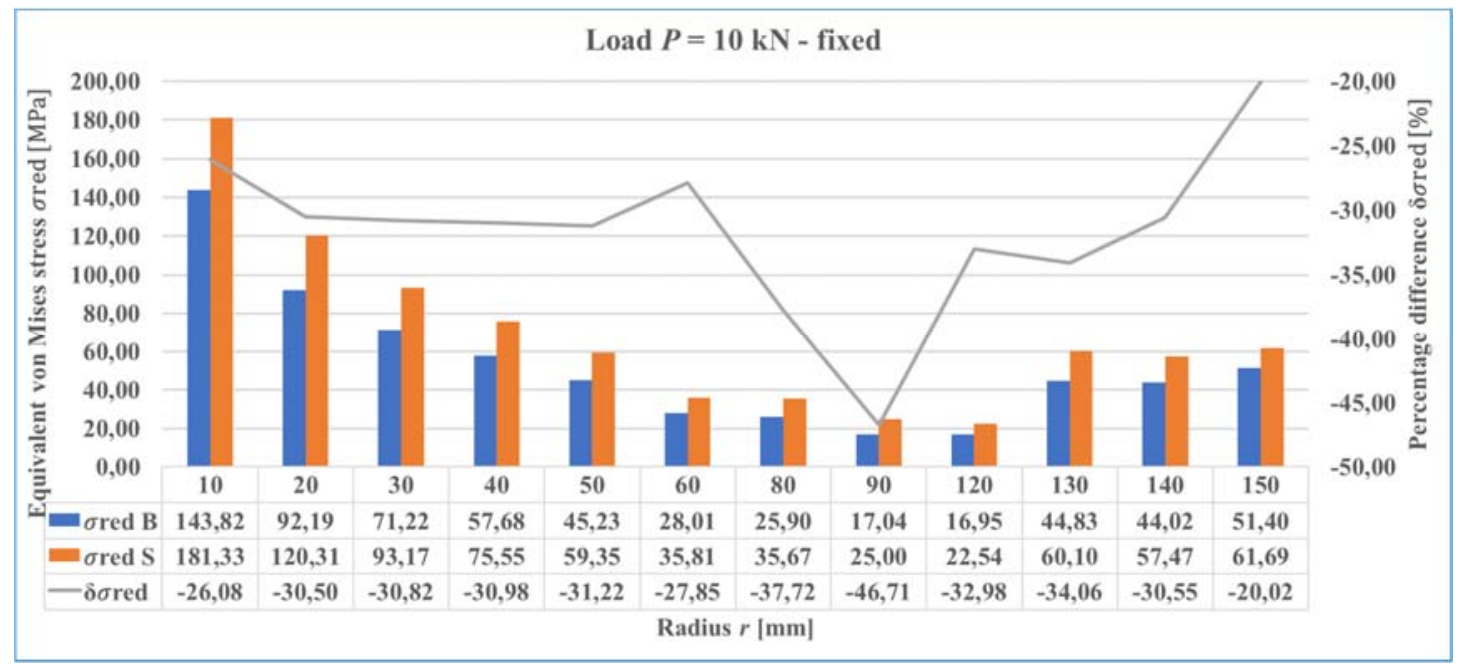

Figure 13: Percentage difference of changes in equivalent von Mises stresses $\delta \sigma_{r e d}^{n}$ determined in the bimetallic plate $\sigma_{r e d_{B}}^{n}$ and in the single-layer plate $\sigma_{r d_{s}}^{n}$, fixed on the perimeter and with a load of $P=10 \mathrm{kN}$. 


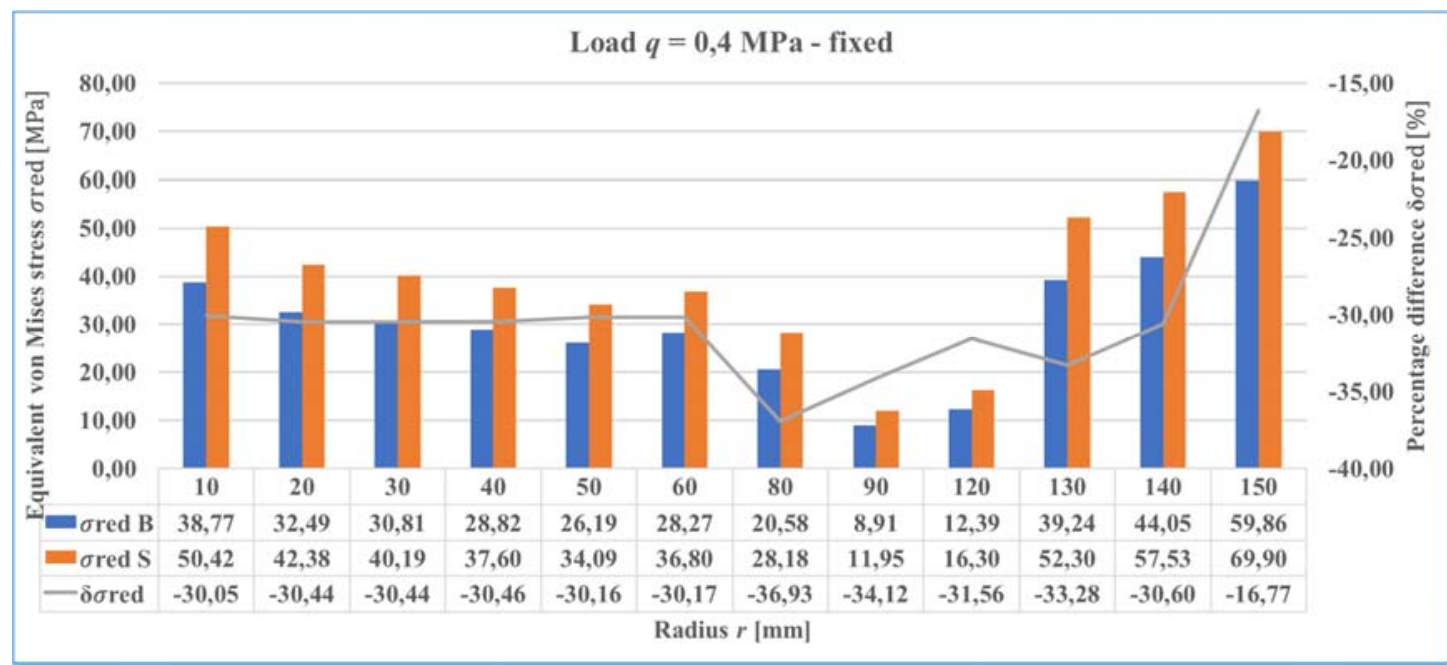

Figure 14: Percentage difference of changes in equivalent von Mises stresses $\delta \sigma_{\text {red }}^{n}$ determined in the bimetallic plate $\sigma_{\text {red }_{B}}^{n}$ and in the single-layer plate $\sigma_{\text {reds }}^{n}$, simply fixed on the perimeter and with a load of $q=0.4 \mathrm{MPa}$.

The diagram in Fig. 11 shows that the maximum difference in the value of the equivalent von Mises stress is about $46 \%$ and occurs at the radius $r=130 \mathrm{~mm}$ in the case of a simply supported plate loaded with a concentrated force $P=10 \mathrm{kN}$. In the case of a simply supported plate and loaded with external pressure $q=0.4 \mathrm{MPa}$, the maximum difference occurs at the radius $r=120 \mathrm{~mm}$ (Fig. 12) and amounts to approx. 47\%. Fixed the plate edges causes the maximum difference in the equivalent von Mises stress in the case of $P=10 \mathrm{kN} \delta \sigma_{\text {red }}^{n}=48 \%$ on the radius $r=90 \mathrm{~mm}$ (Fig. 13). However, in the case of the load $q=0.4 \mathrm{MPa} \delta \sigma_{\text {red }}^{n}=38 \%$ on the radius $r=80 \mathrm{~mm}$ (Fig. 14). From the design engineer's point of view, the zone of the least influence of the state of stress of the applied layer A - titanium on the effort of the bimetallic perforated plate is interesting. Figs. 11-14 show that this is the central zone of the plate from the radius $r=6 \mathrm{~mm}$ to $r=50 \mathrm{~mm}$ and is approx. $\delta \sigma_{\text {red }}^{n}=30 \%$. This reserve of strength due to the presence of the A - titanium applied layer increases the safe operation of the bimetallic perforated plate. It should be mentioned that the main purpose of introducing an applied (titanium) layer in a bimetallic perforated plate is to improve the properties of the plate, such as: corrosion resistance, thermal transmittance, while the task of the base layer is to transfer the load applied to the bimetallic perforated plate. It can be seen from the above that the superimposed layer A - titanium additionally plays a positive role in the effort of the bimetallic perforated plate.

\section{CONCLUSIONS}

$\mathrm{B}$ ased on the tests of the state of stress of bimetallic and single-layer perforated plates and their analysis, the following conclusions can be drawn:

1) It has been shown that in a bimetallic perforated plate subjected to bending compared to a single-layer perforated plate, the equivalent von Mises stress minimally;

2) As the applied layer - titanium was introduced for the purposes of, among others, corrosion resistance, its contribution to the improvement of the strength of the bimetallic perforated plate should be considered a positive feature;

3) It should be noted that the share of the titanium layer in the bimetallic perforated plate contributes to the improvement of the operational safety of structures made of these plates, e.g. process equipment.

\section{APPENDiX A}

T

he base layer of the B - steel plate is combined with the applied layer of the A - titanium plate by using the "connections" function, providing the option to bond two or more elements [14]. It was assumed that the combination of the titanium layer and the steel layer of the plates is excellent. Modeling the connection of these two 
layers, contact was used in the form of inseparable bonding - as both layers were bonded permanently. This type of feature is a default configuration and applies to all contact regions (surfaces, solids, lines, faces, edges, etc.). If the contact areas are stuck together, no shifting or separation between the surfaces or edges is possible. This type of contact allows a linear solution since the contact length / area will not change when the load is applied. A plate made of titanium was used as the contact element, while a steel plate was used as the target element. Details are shown in Fig. A.1.

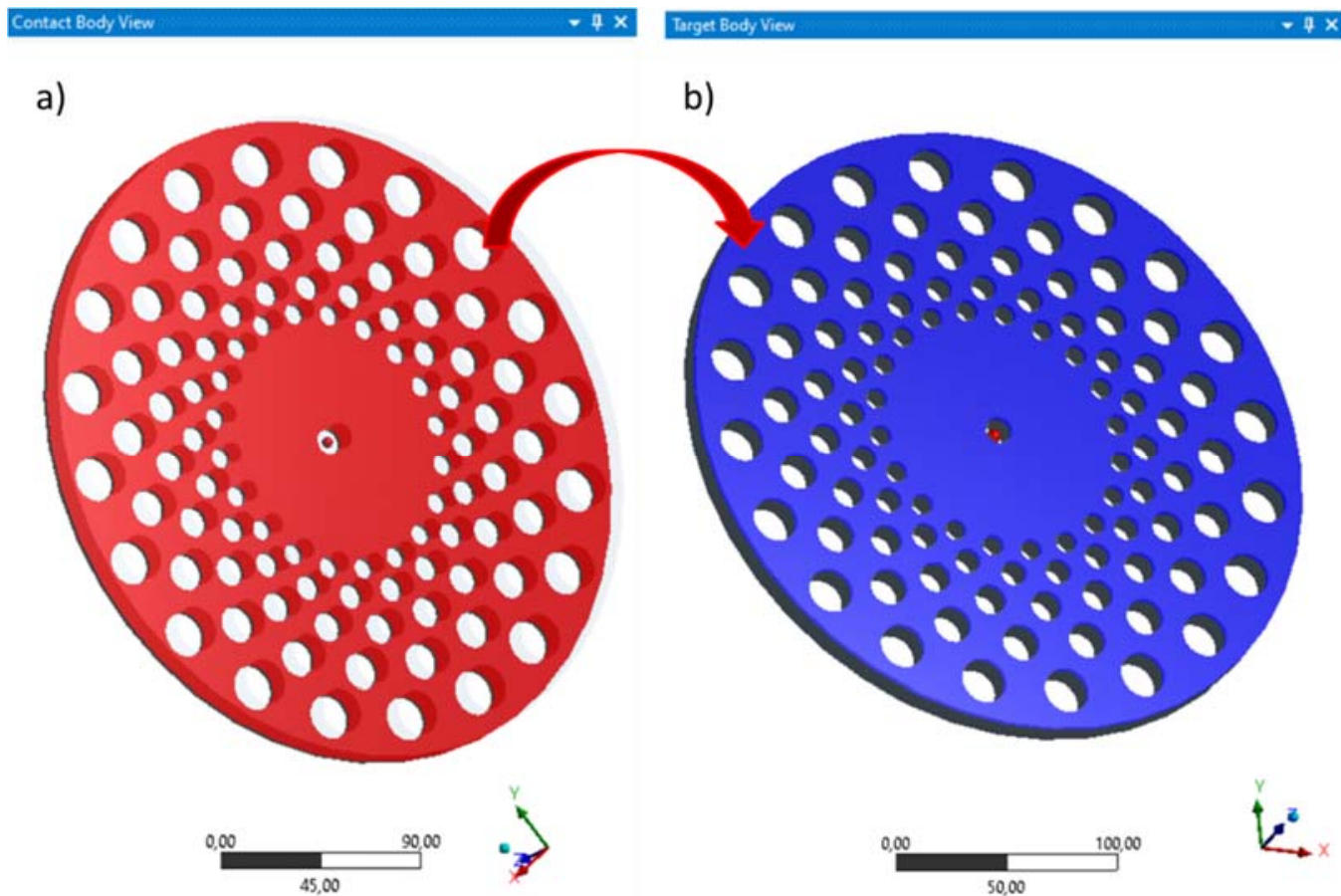

Figure A.1: Application of the connections function between the base layer of the plate and the applied layer of the plate, where: a) contact object view, b) target object view.

\section{REFERENCES}

[1] Gomez, E., Ruiz, R. and Wilson, R. (2013). Asme section III stress analysis of a heat exchanger tubesheet with a misdrilled hole and irregular or thin ligaments. Proceedings of the ASME 2013 Pressure Vessels and Piping Conference Paris, France, pp. $1-8$.

[2] Saraçoğlu, M. and Albayrak, U. (2015). Linear static analysis of perforated plates with round and staggered holes under their self-weights. Research of Engineering Structures and Matirials, 2 (1), pp. $39-47$

[3] Kurek, A., Niesłony, A. and Szulc, Z. (2013). Design of process equipment made from explosively cladded materials, including the imposed material thickness in calculations. Przegląd Mechaniczny, 12, pp. 22-27.

[4] Konieczny, M., Achtelik, H. and Gasiak, G. (2020). Rozkład naprężeń w platerowanej płycie perforowanej obciążanej centralnie siłą skupiona. Studia i Monografie z. 540, Zmęczenie materiału w eksploatacji maszyn roboczych, Oficyna Wydawnicza Politechniki Opolskiej, 2, ss. 47-69 (in Polish).

[5] Chaudhuri, R.A. (1987). Stress concentration around a part through hole weakening laminated plate. Computers and Structures, 27 (2), pp. 601 - 609, DOI: 10.1016/0045-7949(87)90075-7.

[6] Shaikh, E.N., Panchal, K.C. and Patel, D.B. (2015). Stress analysis of an infinite plate with different shaped cutouts in composite plate. International Journal of Science, Technology and Management, 4(1), pp. 307-312.

[7] Kurek, A., Niesłony, A. and Kurek, M. (2014) Stress concentration resulting from irregular shape of explosively cladded materials connections - FEM simulation. Acta Mechanica at Automatica, 8(2), pp. 103-106. DOI 10.2478/ama-2014-0019.

[8] Walczak, W. (1989). Metal explosion welding. WTN, Warsaw (in Polish).

[9] Čížek, L., Ostroushko, D. and Szulc, Z. (2010). Properties of Sandwich Metals Joined by Explosive Cladding Method. Archives of Materials Science and Engineering, 43, pp. 21-29. 
[10]Konieczny, M., Achtelik, H. and Gasiak, G. (2021). Location of stress concentration zones in a two-layer axially symmetrical perforated plate with force applied normally to its surface. Engineering Structures, 226, pp. 1-14. DOI: $10.15199 / 28.2019 .2 .4$.

[11]Konieczny, M., Achtelik, H. and Gasiak, G. (2021). Research of stress distribution in the cross-section of a bimetallic perforated plate perpendicularly loaded with concentrated force. Frattura ed Integrità Strutturale, 55, pp. $241-257$. DOI: $10.3221 /$ IGF-ESIS.55.18.

[12]Konieczny, M., Achtelik, H. and Gasiak, G. (2021). Experimental analysis of the state of stress in a steel - titanium perforated plate loaded with concentrated force. Frattura ed Integrità Strutturale, 55, pp. 277-288. DOI: 10.3221/IGF-ESIS.55.21.

[13]Data from Explomet Company research (Z.T.W. EXPLOMET, Gałka, Szulc, Sp. j. ul. Oświęcimska 100H, 45-641 Opole, Poland).

[14]User's Guide ANSYS 2020 R1, Ansys, Inc., USA. 